\title{
Role of Occupational Stress and Burnout in Prevalence of Musculoskeletal Disorders Among Embassy Personnel of Foreign Countries in Iran
}

\author{
Mashaallah Aghilinejad '; Zargham Sadeghi ${ }^{1, *}$; Amer Abdullah ${ }^{1}$; Shima Sarebanha ${ }^{1}$; \\ Amir Bahrami-Ahmadi ${ }^{1}$ \\ ${ }^{1}$ Occupational Medicine Research Center, Iran University of Medical Sciences, Tehran, IR Iran \\ *Corresponding Author: Zargham Sadeghi, Occupational Medicine Research Center, Iran University of Medical Sciences, Tehran, IR Iran. Tel/Fax: +98-2188622682, \\ E-mail:iranomrc@gmail.com
}

Received: November 10, 2012; Revised: October 6, 2013; Accepted: November 26, 2013

\begin{abstract}
Background: Occupation is one of the major parts of our daily lives that might cause a great amount of stress. Stress and job burnout are linked together. The association between musculoskeletal disorders (MSD) and burnout syndrome as a psychosocial factor was investigated previously.

Objectives: The aim of this study was to identify the role of occupational stress and burnout in musculoskeletal complaint among diplomatic employees of different embassies in Iran.

Materials and Methods: In a cross-sectional study, we assessed 200 employees of the foreign countries embassies in Iran. The participants were selected randomly from all the embassy personnel. Study questionnaires were delivered to the participants and finally 161 questionnaires were returned to the researchers (response rate: 80.5\%). An assessment of burnout and MSD were made using the Maslach Burnout Inventory (MBI) and Nordic questionnaires. The work place stress was measured by the work place stress questionnaire.

Results: Mean occupational stress was significantly higher among embassy personnel with MSD than among the personnel without this syndrome during the preceding week (17.18 \pm 3.42 and $16.06 \pm 2.19$, respectively; $\mathrm{P}=0.02)$ and the preceding year (17.17 \pm 3.11 and $16.74 \pm 3.03$, respectively; $\mathrm{P}<0.01$ ) to the study. Only smoking and occupational stress were identified as independent predictors of MSD among embassy personnel.

Conclusions: It seems that association between musculoskeletal complaints and burnout syndrome was more complex than being attributed to only occupation stress. Further studies are recommended to determine other related factors to this association.
\end{abstract}

Keywords: Burnout; Professional; Musculoskeletal Diseases; Occupational Stress; Embassy Personnel

\section{Background}

Burnout is a psychological term that infers an excessive stress reaction to the prolonged exposure to occupational or professional stressors $(1,2)$. Burnout is often defined as the result of chronic work stress (3). If workers are unable to cope with stress factors, it might lead to multiple complications. One of the important issues of prolonged stress is burnout. The three difference dimensions of burnout are emotional exhaustion, depersonalization, and lack of personal accomplishment. Burnout has been a major topic of research throughout world. It is discussed in many studies and it has been investigated in more than 4500 studies (3).

Occupational life is one of the major parts of our daily lives that might cause a great amount of stress (4). Stress and professional burnout can be linked together. Burnout has psychological and physical symp- toms including reduced energy, fatigue, weakness, chronic headache, musculoskeletal disorders (MSD), back pain, multiple physical complication, and sleep disorders (5).

The MSD are multifactorial in origin and several factors such as physical and psychological factors might contribute to their progression and persistence. Previous studies reported that sustained sitting posture during working in offices accompanied with poor ergonomic status of workplaces were among the significant causes of musculoskeletal symptoms development in office workers. The association between MSD and burnout syndrome as a psychosocial factor was investigated in previous studies $(1,5-8)$. Some of these studies confirmed the association between musculoskeletal complaints and burnout as a whole construct, or as a summation of its three dimensions (1, 9-11).

Implication for health policy/practice/research/medical education:

Present study was first study in this field and some intervention was need in this case.

Copyright (C) 2014, Iranian Red Crescent Medical Journal; Published by Kowsar Corp. This is an open-access article distributed under the terms of the Creative Commons Attribution License, which permits unrestricted use, distribution, and reproduction in any medium, provided the original work is properly cited. 


\section{Objectives}

Political diplomats of foreign embassies had specific work with stressful workplace and up to our searching on the literature, we did not find the same research for association between job stress, professional burnout, and MSD among diplomats and our study might be the first study in this filed. The aim of this study was to identify the role of occupational stress and burnout in musculoskeletal complaint among diplomatic employees of different embassies in Iran.

\section{Materials and Methods}

\subsection{Study Population}

In this cross-sectional study, we assessed the personnel of the foreign countries embassies in Tehran, Iran. All of the embassies personal in any part of foreign embassies were eligible for participating. The personal with bone fractures as well as systemic or tumoral bone disorders were excluded. According to the sample size formula $(\mathrm{P}=0.5$ and $\mathrm{d}=0.05)$ at least 50 individuals would be needed. We prepared a list of foreign embassies in Iran and among them, due to availability of study population and without need for more expenditure on larger sample size, we randomly selected 200 individuals as study participants. Study questionnaire were distributed among the participants and finally 161 questionnaires were returned to the researchers (response rate: 80.5\%). Present study was approved by Ethical Committee of Iran University of Medical Sciences and informs consents were signed by all of the participants.

\subsection{Data Gathering Instruments}

In this study, basal variables of embassy personnel including their age, gender, education, body mass index (BMI), marital status, smoking, and past medical history were collected via study check list. The professional burnout was assessed by the Maslach Burnout Inventory (MBI). This scale consists of 19 questions relating to the three components of burnout including personal, workrelated, and client-related burnout. Personal burnout is a state of prolonged physical and psychological exhaustion and is assessed by six questions. Work-related burnout is a state of prolonged physical and psychological exhaustion, which is perceived as related to the person's work, assessed by five questions. Client-related burnout is a state of prolonged physical and psychological exhaustion, which is perceived as related to the person's work with client, is measured using six questions. The items were scored using a five-point scale from zero to 100. The MBI had been used in the previous studies for assessment of burnout in several fields such as health care (12-14) as well as teachers and students $(15,16)$.

Data of musculoskeletal complaints were gathered by means of Standardized Nordic Self-Reporting
Questionnaire. This questionnaire includes questions such as age, duration of occupation as a worker, weight of carried loads, daily working hours, and musculoskeletal complaints in each of the following body regions: neck, shoulder, elbow, wrist/hand, upper back, lumbar, one or both hips/thighs, one or both knees, and one or both ankle/feet. Data on daily working hours were measured by considering the time spent in the workplace. The validity and reliability of the questionnaire has been approved in different studies. Musculoskeletal complaint was defined as pain or discomfort experienced in soft tissue of the different body regions, which had occurred at least during two to three work days in the preceding week or preceding 12 months. Moreover, the pain improvement on the weekends, vacations, and holidays had to be noted. Research team supervised all medical records and questionnaire filling. Several studies were used Nordic questionnaire as instrument of assessment of MSD prevalence among workers of different workplaces $(17,18)$. The workplace stress was measured by the workplace stress questionnaire. The scale was developed by the Marlin Company, North Haven, CT, USA, and the American Institute of Stress, Yonkers, NY, USA. This scale included eight parts. Responses were scored using a five-point scale ranging from zero (Never) to four (Very often). This scale was used to assess the role of occupational stress in development of other factors among workers (19).

\subsection{Statistical Analysis}

Data were presented as mean \pm standard deviation for continues variables and frequency (percentage) for discreet variables. Chi squared test was used to compared demographic and qualitative variable between workers with and without musculoskeletal complaints. Quantitative variables were compared between two noted groups using independent student sample t-test. Logistic regression analysis with enter model was performed to determine independent predictors of musculoskeletal complaints among embassy personnel. Age, work history, smoking, stress score, body mass index, general health scores, as well as personal, work-related, and client-related burnout were entered into the logistic regression model. Remained variables into the model were identified as independent predictors of MSD among embassy personnel. Statistical analysis was performed in SPSS (SPSS Inc., Chicago, IL, USA). P values $<0.05$ were assumed as statistically significant results.

\section{Results}

Finally, 161 questionnaires were returned to the researchers. Our participants consisted of 87 males. The mean age and work history of the study participants were $39.32 \pm 6.66$ and $9.43 \pm 6.21$ years, respectively. Most of study participants have master of science (104 participants; 64.6\%) as educational degree. Mean BMI in the study population was $24.08 \pm 2.88$. Among study partici- 
pants, 129 (80.1\%) persons were married and 86 (53.4\%) persons were smoker. The mean of general health scores in embassy personnel was $19.69 \pm 2.12$. Among embassy personnel, the mean of occupation stress was $16.74 \pm 3.03$ and accordingly, most of the study participants were classified as fairly low 93 (57.8\%) group.

\subsection{Musculoskeletal Complaints Prevalence in Em- bassy Personnel at Preceding Week and Year}

Prevalence of MSD in embassy personnel during the preceding week and year in different body parts were $59.6 \%$ and $75.2 \%$, respectively. Musculoskeletal complaints in the preceding week were most commonly reported in the neck (29.80\%), the wrist(s) (26.10\%), lower back (19.9\%), and upper back (16.80\%) consecutively; in 12-month period, these rates were most commonly at the neck (49.70\%), wrist(s) (36\%), lower back (34.20\%), and upper back (29.20\%), consecutively. In the preceding year, workers reported that musculoskeletal complaints of wrist(s) (3.7\%), lower back, Knee(s), and shoulder (2.5\%), consecutively, caused limitation in their function. Details of other MSD prevalence were reported in Table 2 and 3 (Table 1 ).

\subsection{Burnout Situation Among Embassy Personnel}

According to results of MBI, mean of personal, workrelated, and client-related burnout scores were $73.65 \pm$ $15.71,73.09 \pm 14.11$, and $76.40 \pm 10.30$, respectively. Mean of personal burnout score in smoker, those with master of science degree, and stressful embassy personnel was significantly higher than in other personnel. Mean of workrelated burnout in embassy personnel with master of science degree and in stressful personnel was significantly higher than in other personnel. Mean of client-related burnout in embassy personnel with more than 20 years

Table 1. Musculoskeletal Disorders Prevalence During Preceding Week and Year in Participants $(\mathrm{n}=161)^{\mathrm{a}}$

\begin{tabular}{lcc}
\hline & $\begin{array}{c}\text { MSD } \\
\text { During Prevalence } \\
\text { Week }\end{array}$ & $\begin{array}{c}\text { MSD Prevalence } \\
\text { During Preceding } \\
\text { Year }\end{array}$ \\
\hline Neck & $48(29.8)$ & $80(49.7)$ \\
\hline Wrist/hand & $42(26.10)$ & $58(36)$ \\
Lumbar & $32(19.9)$ & $55(34.2)$ \\
Upper back & $27(16.8)$ & $47(29.2)$ \\
\hline $\begin{array}{l}\text { Shoulder } \\
\text { One or both knees }\end{array}$ & $12(6.2)$ & $14(8.7)$ \\
$\begin{array}{l}\text { One or both } \\
\text { hips/thighs }\end{array}$ & $8(5)$ & $12(7.5)$ \\
$\begin{array}{l}\text { Elbow } \\
\begin{array}{l}\text { One or both } \\
\text { ankle/feet }\end{array}\end{array}$ & $2(1.2)$ & $2(1.2)$ \\
\hline $\begin{array}{l}\text { a Data are presented as No.(\%). } \\
\text { b Musculoskeletal disorders }\end{array}$ & - & $2(1.2)$ \\
\hline
\end{tabular}

work history, stressful, and older than 50 years old was significantly higher than in other personnel.

\subsection{Occupational Stress and Burnout Among Em- bassy Personnel With and Without Musculoskel- etal Disorders}

Mean of occupational stress in embassy personnel with MSD at the preceding week was significantly higher than in embassy personnel without MSD (17.18 \pm 3.42 and

Table 2. Mean of Subscales of Professional Burnout Among Embassy Personnel ${ }^{\text {a,b }}$

\begin{tabular}{|cccc}
\hline Study Variables & $\begin{array}{c}\text { Personal } \\
\text { Burnout }\end{array}$ & Work Burnout & $\begin{array}{c}\text { Client Burn- } \\
\text { out }\end{array}$ \\
\hline Sex & & & \\
\hline Male & $79.90 \pm 15.72$ & $73.19 \pm 14.44$ & $76.87 \pm 10.42$ \\
\hline Female & $72.18 \pm 15.67$ & $72.97 \pm 13.80$ & $75.84 \pm 10.21$ \\
\hline P value & 0.27 & 0.92 & 0.53 \\
\hline Marital status & & & \\
\hline Single & $73.96 \pm 16.22$ & $72.70 \pm 14.24$ & $76.97 \pm 10.32$ \\
\hline Married & $73.57 \pm 15.64$ & $72.70 \pm 14.24$ & $76.97 \pm 10.37$ \\
\hline P value & 0.90 & 0.48 & 0.16 \\
\hline Smoking & & & \\
\hline Smoker & $76.36 \pm 15.37$ & $74.21 \pm 15.50$ & $76.26 \pm 9.70$ \\
\hline Non-smoker & $70.56 \pm 15.61$ & $76.44 \pm 11.01$ & $71.80 \pm 12.29$ \\
\hline P value & 0.019 & 0.28 & 0.96 \\
\hline Work history, y & & & \\
\hline$<5$ & $74.71 \pm 14.80$ & $74.92 \pm 12.39$ & $74.53 \pm 6.86$ \\
\hline $5-10$ & $74.22 \pm 13.60$ & $73.45 \pm 11.12$ & $74.46 \pm 9.85$ \\
\hline $10-15$ & $70.51 \pm 21.37$ & $69.92 \pm 20.78$ & $78.85 \pm 13.01$ \\
\hline $15-20$ & $74.40 \pm$ & $74.49 \pm 18.42$ & $80.96 \pm 11.75$ \\
\hline$>20$ & 16.89 & & $87.50 \pm 8.33$ \\
\hline P value & $71.87 \pm 16.77$ & $67.86 \pm 11.77$ & 0.001 \\
\hline Ag & 0.84 & 0.51 & \\
\hline
\end{tabular}

Age groups, $y$

\begin{tabular}{lccc}
$<29$ & $67.86 \pm 18.74$ & $76.53 \pm 11.82$ & $76.19 \pm 14.77$ \\
$30-39$ & $73.91 \pm 15.06$ & $74.03 \pm 12.01$ & $75.13 \pm 7.02$ \\
$40-49$ & $74.50 \pm$ & $72.36 \pm 18.16$ & $75.69 \pm 13.65$ \\
& 16.49 & & \\
\hline $50-59$ & $72.39 \pm 17.07$ & $67.86 \pm 14.52$ & $85.94 \pm 10.53$ \\
\hline P value & 0.76 & 0.37 & 0.001
\end{tabular}

BMI groups

\begin{tabular}{lccc}
$<20$ & $70.83 \pm 5.89$ & $73.21 \pm 2.52$ & $72.92 \pm 2.95$ \\
$20-25$ & $74.26 \pm 14.89$ & $74.94 \pm 13.10$ & $75.41 \pm 9.35$ \\
$25-30$ & $73.58 \pm 17.42$ & $68.82 \pm 16.31$ & $78.86 \pm 12.31$ \\
$>30$ & $61.67 \pm 73.66$ & $66.43 \pm 12.27$ & $80.00 \pm 12.97$ \\
\hline P value & 0.37 & 0.07 & 0.24 \\
\hline
\end{tabular}

a Abbreviation: BMI, body mass index.

$\mathrm{b}$ Data are presented as mean $\pm \mathrm{SD}$. 
Table 3. Comparison of Study Variables Among Embassy Personnel According Their Musculoskeletal Disorder Situation ${ }^{\mathrm{a}, \mathrm{b}}$

\begin{tabular}{lccc}
\hline Study Variables & MSD Present & No MSD & P value \\
\hline Sex & & & 0.38 \\
\hline Male & $23(57.5)$ & $17(52.9)$ & \\
Female & $64(42.5)$ & $57(47.1)$ & \\
\hline Marital status & & & 0.65 \\
\hline Single & $9(22.5)$ & $23(19)$ & \\
\hline Married & $31(77.5)$ & $98(81)$ & \\
\hline Smoking & & & 0.01 \\
\hline Smoker & $14(35)$ & $72(59.5)$ & \\
\hline Non-smoker & $26(65)$ & $49(40.5)$ & \\
\hline Work history, y & & & $<0.001$ \\
\hline$<5$ & $12(30)$ & $32(26.4)$ & \\
\hline $5-10$ & $8(20)$ & $61(50.4)$ & \\
\hline $10-15$ & $12(30)$ & $14(11.6)$ & \\
\hline $15-20$ & $4(10)$ & $10(8.3)$ & \\
\hline$>20$ & $4(10)$ & $4(3.3)$ & \\
\hline Age groups, y & & & \\
\hline$<29$ & $17(2.5)$ & $1(0.8)$ & \\
\hline $30-39$ & $21(52.5)$ & $92(76)$ & \\
\hline $40-49$ & $17(42.5)$ & $24(19.8)$ & \\
\hline $50-59$ & $1(2.5)$ & $4(3.4)$ & \\
\hline BMI groups & $4(10)$ & $12(9.9)$ & \\
\hline$<20$ & & & \\
\hline $20-25$ & & & \\
\hline $25-30$ & & & \\
\hline$>30$ & & & \\
\hline
\end{tabular}

a Abbreviations: BMI, body mass index; MSD, musculoskeletal disorder.

$\mathrm{b}$ Data are presented as No. (\%).

$16.06 \pm 2.19$, respectively; $\mathrm{P}=0.02$ ). Mean of occupational stress in embassy personnel with MSD at the preceding year was significantly higher than in embassy personnel without MSD (17.17 \pm 3.11 and $16.74 \pm 3.03$, respectively; P $<0.01)$. Mean of three subscales of burnout were significantly higher in embassy personnel with MSD in comparison with others.

\subsection{Results of Logistic Regression Analysis}

In our logistic regression analysis, after entering study variables including age, work history, BMI, smoking, occupational stress score, GHQ (General Health Questionnaire) score, personal, and work-related as well as client-related burnout into the model, only smoking and occupational stress score remained in our model. In other words, the impact of other study variables on prevalence of musculoskeletal complains was due to other factors and only smoking and occupational stress were
Table 4. Results of Regression Analysis in Embassy Personnel ${ }^{a}$

\begin{tabular}{|c|c|c|c|c|c|}
\hline & \multirow[t]{2}{*}{ Beta } & \multicolumn{2}{|c|}{$\begin{array}{l}\text { Standard Significances } \\
\text { Error }\end{array}$} & \multicolumn{2}{|c|}{$\begin{array}{c}95.0 \% \text { CI for } \\
\operatorname{Exp}(B)\end{array}$} \\
\hline & & & & Upper & Lower \\
\hline Constant & 1.25 & 4.89 & 0.96 & - & - \\
\hline Age & 1.11 & 0.089 & 0.20 & 0.93 & 1.32 \\
\hline Work history & 0.89 & 0.088 & 0.20 & 0.75 & 1.06 \\
\hline Smoking & 3.78 & 0.509 & 0.009 & 1.39 & 10.26 \\
\hline Stress score & 1.37 & 0.124 & 0.01 & 1.08 & 1.75 \\
\hline BMI & 0.90 & 0.089 & 0.25 & 0.76 & 1.08 \\
\hline $\begin{array}{l}\text { Personal } \\
\text { burnout }\end{array}$ & 0.99 & 0.024 & 0.57 & 0.94 & 1.03 \\
\hline $\begin{array}{l}\text { Work-related } \\
\text { burnout }\end{array}$ & 0.97 & 0.025 & 0.16 & 0.92 & 1.01 \\
\hline $\begin{array}{l}\text { Client-related } \\
\text { burnout }\end{array}$ & 0.96 & 0.026 & 0.21 & 0.92 & 1.02 \\
\hline GHQ score & 1.05 & 0.046 & 0.70 & 0.83 & 1.32 \\
\hline
\end{tabular}

a Abbreviations: CI, confidence interval; GHQ, general health questionnaire; BMI, body mass index.

known as independent predictor of MSD among embassy personnel (Table 4).

\section{Discussion}

Finally, 161 questionnaires were returned to the researchers. Mean of personal and work-related burnout score in smoker, those who hold a master of science degree, and stressful embassy personnel were significantly higher than other personnel. Mean of client-related burnout in embassy personnel with more than 20 years work history, stressful individuals, and those older than 50 years was significantly higher than the others. Mean of three subscales of burnout were significantly higher in embassy personnel with MSD in comparison with the others. Only smoking and occupational stress were identified as independent predictor of MSD among embassy personnel.

The main purpose of the present study was to determine MSD prevalence among embassy personnel of foreign countries in Iran as well as to evaluate the association of MSD prevalence with work-related factors such as occupational stress or burnout. Psychological factors such as occupational stress and burnout had impacts on musculoskeletal complaints (20). Findings of our study showed that although stress and burnout were significantly higher in embassy personnel with MSD, occupational stress had not any mediatory role in this process. In their study on different work groups, Kjellbberg and Wadman reported that stress in workers differed from burnout, although both of them were closely related to each other (20). Similar findings were reported in Maslach and Schaufeli study (21).

Burnout is related to loss of energy and might occur in both physical and psychological part of human life. 
People who experience burnout most of the times, progressively loss their idealism, energy, and purpose (22). In some studies, burnout concept was defined in three main parts: emotional exhaustion, depersonalization, and lack of personal and professional completion $(22,23)$. Results of binary logistic regression among study variables of the present study showed that most of the suspected factors such as age, sex, work history, and other factors were dependent predictor of MSD in the workers. On the other hand, some other and non-related factors were effective in burnout development among workers. Our study results were similar to the results of the study by Larsman et al. in which few percentage of MSD cases were related to the occupational stress and professional burnout (24). Several previous studies confirmed the association of burnout syndrome with the presence and development of MSD among workers $(5-8,25)$.

It seems that association between musculoskeletal complaints and burnout syndrome was more complex than being attributed to occupation stress only. Musculoskeletal complaints were related to muscular tension, one of the main findings in workers with high stress level. Larsman and Hanse reported that low social support and psychological stimuli were associated with increasing risk of neck, shoulder, and low back pain (26).

Embassy personnel are the professional workers who spend most of their time in embassies in the several countries with different socioeconomically and cultural conditions. They possibly confront with many stressors and it might lead to burnout development. According to study findings for assessment and control of burnout in embassy personnel, besides psychological factors such as occupational stress, we must pay more attention to other mediated factors such as work environment, ergonomic situation, and different cultural conditions.

Strength of our study was its study population. According to our searching in the literature, this study we did not find study that evaluate role of burnout or other psychological factors on MSD development among embassy personnel up to the date of performing. Present study had some limitations; firstly, we only selected some embassy personnel due to security and political considerations. Secondly, burnout is a psychological concept and its measurement tools had to be defined more clearly to the participants to increase study accuracy. Thirdly, embassy personnel of several countries had social and economic differences; hence, it seems that stratified sampling method is a better sampling method for the future studies.

\section{Acknowledgements}

There is no acknowledgment.

\section{Authors' Contribution}

All authors contributed equally in writing the manuscript.

\section{Financial Disclosure}

There is no financial disclosure.

\section{Funding/Support}

There are no funding supports.

\section{References}

1. Jaworek M, Marek T, Karwowski W, Andrzejczak C, Genaidy AM. Burnout syndrome as a mediator for the effect of work-related factors on musculoskeletal complaints among hospital nurses. Int J Ind Ergonom. 2010;40(3):368-75.

2. Le Gall JR, Azoulay E, Embriaco N, Poncet MC, Pochard F. [Burn out syndrome among critical care workers]. Bull Acad Natl Med. 2011;195(2):389-97; discussion 97-8.

3. Milfont TL, Denny S, Ameratunga S, Robinson E, Merry S. Burnout and Wellbeing: Testing the Copenhagen Burnout Inventory in New Zealand Teachers. Soc Indic Res. 2008;89(1):169-77.

4. Ahsan N, Abdullah Z, Fie DG, Alam SS. A study of job stress on job satisfaction among university staff in Malaysia: Empirical study. EurJ Soc Sci. 2009;8(1):121-31.

5. Alexopoulos EC, Burdorf A, Kalokerinou A. Risk factors for musculoskeletal disorders among nursing personnel in Greek hospitals. Int Arch Occup Environ Health. 2003;76(4):289-94.

6. Ariens GAM, van Mechelen W, Bongers PM, Bouter LM, van der Wal G. Psychosocial risk factors for neck pain: A systematic review. Am J Ind Med. 2001;39(2):180-93.

7. Byrns G, Reeder G, Jin G, Pachis K. Risk factors for work-related low back pain in registered nurses, and potential obstacles in using mechanical lifting devices. J Occup Environ Hyg. 2004;1(1):11-21.

8. Smith DR, Mihashi M, Adachi Y, Koga H, Ishitake T. A detailed analysis of musculoskeletal disorder risk factors among Japanese nurses. J Safety Res. 2006;37(2):195-200.

9. Grossi G, Soares JJ, Angesleva J, Perski A. Psychosocial correlates of long-term sick-leave among patients with musculoskeletal pain. Pain.1999;80(3):607-19.

10. Soares JJ, Jablonska B. Psychosocial experiences among primary care patients with and without musculoskeletal pain. Eur J Pain. 2004;8(1):79-89.

11. Toppinen-Tanner S, Ojajarvi A, Vaananen A, Kalimo R, Jappinen P. Burnout as a predictor of medically certified sick-leave absences and their diagnosed causes. Behav Med. 2005;31(1):18-27.

12. Gupta S, Paterson ML, Lysaght RM, von Zweck CM. Experiences of burnout and coping strategies utilized by occupational therapists. Can J Occup Ther. 2012;79(2):86-95.

13. Siu C, Yuen SK, Cheung A. Burnout among public doctors in Hong Kong: cross-sectional survey. Hong Kong Med J. 2012;18(3):186-92.

14. Wu S, Li H, Zhu W, Lin S, Chai W, Wang X. Effect of work stressors, personal strain, and coping resources on burnout in Chinese medical professionals: a structural equation model. Ind Health. 2012;50(4):279-87.

15. Pishghadam R, Sahebjam S. Personality and emotional intelligence in teacher burnout. Span J Psychol. 2012;15(1):227-36.

16. Fang DZ, Young CB, Golshan S, Moutier C,Zisook S. Burnout in premedical undergraduate students. Acad Psychiatry. 2012;36(1):11-6.

17. Aghilinejad M, Choobineh AR, Sadeghi Z, Nouri MK, Bahrami Ahmadi A. Prevalence of Musculoskeletal Disorders among Iranian Steel Workers. Iran Red Crescent Med J. 2012;14(4):198-203.

18. Aghilinejad M, Javad Mousavi SA, Nouri MK, Ahmadi AB. Work-related musculoskeletal complaints among workers of Iranian aluminum industries. Arch Environ Occup Health. 2012;67(2):98-102.

19. McCalister KT, Dolbier CL, Webster JA, Mallon MW, Steinhardt MA. Hardiness and support at work as predictors of work stress and job satisfaction. Am J Health Promot. 2006;20(3):183-91.

20. Kjellberg A, Wadman C. The role of the affective stress response as a mediator of the effect of psychosocial risk factors on musculoskeletal complaints-Part 1: Assembly workers. Int J Ind Ergonom. 2007;37(4):367-74. 
21. Maslach C, Schaufeli WB. Historical and conceptual development of burnout. In: Schaufeli WB, Maslach C, Marek T, editors. Professional Burnout Recent Developments in Theory and Research. Washingtone DC: Taylor \& Francis; 1993. p. 1-16.

22. Maslach C. What have we learned about burnout and health? Psychol Health. 2001;16(5):607-11.

23. Maslach C, Leiter M. The truth about burnout. How organizations cause personal stress and what to do about it. San Francisco, CA: Jossey-Bass; 1997.

24. Larsman P, Sandsjo L, Klipstein A, Vollenbroek-Hutten M,
Christensen H. Perceived work demands, felt stress, and musculoskeletal neck/shoulder symptoms among elderly female computer users. The NEW study. Eur J Appl Physiol. 2006;96(2):127-35.

25. Trinkoff AM, Lipscomb JA, Geiger-Brown J, Storr CL, Brady BA. Perceived physical demands and reported musculoskeletal problems in registered nurses. Am J Prev Med. 2003;24(3):270-5.

26. Larsman P, Hanse JJ. The impact of decision latitude, psychological load and social support at work on the development of neck, shoulder and low back symptoms among female human service organization workers. Int J nd Ergonom. 2009;39(2):442-6. 